\title{
Lessons from an ancestor
}

The theory that cancer cells form a hierarchy in which a tumour is maintained by a sub-population of cells with stem-like properties has generated a lot of interest, but little is known about the early mutations that have an effect in cancer, and the precancerous cells in which they occur. Tariq Enver's group investigated precancerous cells in a set of twins of whom only one developed acute lymphoblastic leukaemia (ALL).

ALL is commonly associated with a chromosomal translocation $($ TEL-AML1) that is present in preB-cells during embryogenesis. This results in a clone of pre-leukaemic cells that, with further mutations, can become leukaemogenic. A set of monochorionic twins provided a unique opportunity to study these precancerous cells, because during their development one of the twins developed the TEL-AML1 fusion and cells containing this fusion then spread to the other through the placenta. The affected twin developed ALL, allowing the group to examine the 'ancestral' pre-leukaemic cell in the healthy twin.

A distinct population of CD $34^{+} \mathrm{CD} 38^{- \text {-low }} \mathrm{CD} 19^{+}$cells are present in patients with ALL and when Enver's team tested cells with this immunophenotype for leukaemogenic potential they found that they do indeed have stem-like properties, including the capability to self-renew and differentiate. Bone marrow from the leukaemic twin contained a CD $34^{+} \mathrm{CD} 38^{-/ \text {low }} \mathrm{CD} 19^{+}$ population in which the uninvolved TEL allele had been lost, whereas the peripheral blood of the healthy twin contained $\mathrm{CD} 19^{+}$cells harbouring the translocation but retaining the second copy of TEL, indicative of a pre-leukaemic state. A low frequency of $\mathrm{CD} 34^{+} \mathrm{CD} 38^{- \text {/low }} \mathrm{CD} 19^{+}$cells were observed in peripheral blood from the healthy twin, and the levels of these cells have been stable for the last 18 months.

By examining the extent of immunoglobulin heavy chain gene rearrangement, the authors found that the $\mathrm{CD} 34^{+} \mathrm{CD} 38^{-/ \text {low }} \mathrm{CD} 19^{+}$cells from both twins were clonal. This suggested that the population in the leukaemic twin is a more developed and differentiated descendent of the population in the healthy twin. Further experiments suggested that the TEL-AML1 translocation alone is enough to generate abnormal, pre-leukaemic cells resembling those observed in the healthy twin. Interestingly CD38-/low expression was crucial for leukaemogenic potential.

The group were fortunate to be able to study the twins and examine precancerous cells that are clinically completely silent. Will screening children for pre-leukaemic clones become common? Not likely, says Enver; as a priority we still need to develop less toxic treatments for this disease and understand how precancerous cells transform. Enver's team hope to use this information to understand how TEL-AML1 induces changes within cells that can lead to further oncogenic events.

Simone Alves

ORIGINAL RESEARCH PAPER Hong, D. et al. Initiating and cancer-propagating cells in TELAML1-associated childhood leukemia. Science 319, 336-339 (2008)

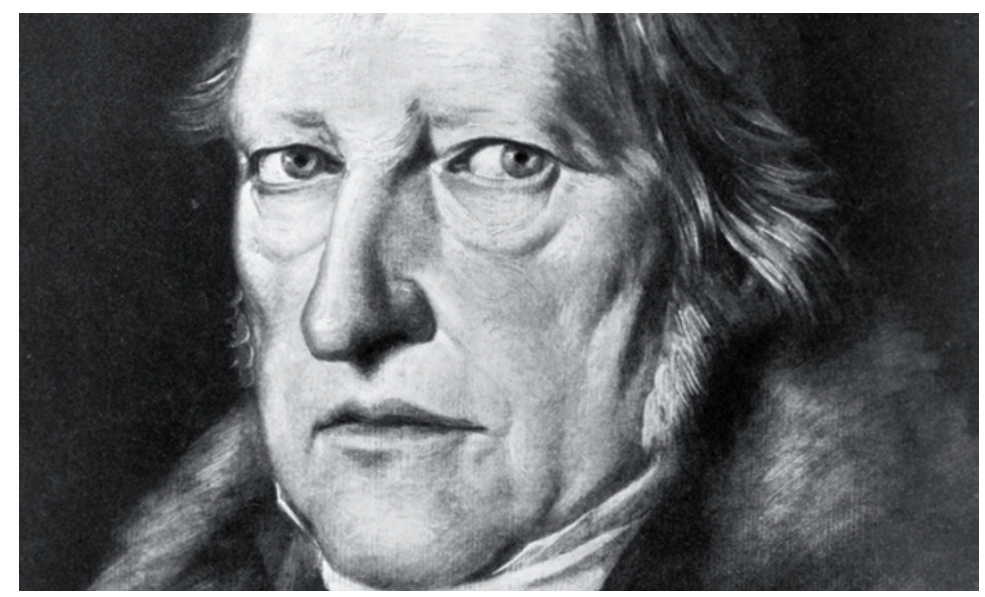

